\title{
'HEDGING' AND GENDER IN PARTICIPATORY DESIGN
}

\author{
Alice Ashcroft \\ Lancaster University \\ School of Computing and Communications, Lancaster University, Lancaster, UK
}

\begin{abstract}
There has been much dispute over the role 'hedging' - equivocation in expressing opinions - plays in group conversation as well as the impact of gender on a range of processes including Participatory Design; (Holmes, 1986, Dixon and Foster, 1997, Stokoe and Smithson, 2001, Stokoe and Weatheral, 2002, Brulé, E. and Spiel, K. (2019),). This paper addresses these issues by analysing gender differences and hedging in an Innovation Participatory Design workshop focused around the creation and combination of ideas for app development. Discussions were transcribed and analysed; 'hedging' terms seemed an interesting theme for analysis, but no statistical significance was found to prove that 'hedging' was gender-biased. This initial, exploratory, short paper reflects on this finding; on the contrast with research that has found gender differences (Holmes, 1986); on the importance of supplementing statistical with contextual forms of analysis; and what effect or implications this may have on the process of Participatory Design, by acknowledging the importance of giving voice and parity, and trying to facilitate group dynamics that properly reflect the views of all participants.
\end{abstract}

\section{KEYWORDS}

Hedging, Participatory Design, Gender

\section{INTRODUCTION}

Gender has long been considered an important factor in shaping participation in STEM subjects including Design. Consequently, when considering Participatory Design (PD) as an approach to system development it's important to consider the effect that gender might play, especially in a group setting (Rommes, E., 2006; Buchmuller et al., 2011; Bleijenbergh, I. and Van Engen, M., 2015); that gender is one of the "different identities negotiated both through personal interactions and in the materials used and objects created during the participatory design processes" (Brule and Spiel, 2019). An initial analysis of a PD innovation workshop suggested the possibility that gender differences in language use might impact on levels, forms and types of participation. Of particular interest was the possible different use of 'hedging' terms. Hedging refers to the idea of uncertainty, of "hedging' your bets' with phrases such as "I think", "you know" and "sort of" (Murphy, 2010, Holmes, 1986, Holmes, 1990). Hedging is recognised as a "significant communicative resource" (Hyland, 1996). Some suggest gender plays a role in hedging; Murphy (2010) for example, states that "the use of hedges among females before a key word" is used "to avoid the appearance of playing the expert". Holmes (1986) states that hedging has two purposes, either to express speaker confidence e.g. "you know" or "reflecting uncertainty" e.g. "I think". Research by Dixon and Foster (1996) found that hedging was used the same number of times by both genders, (contradicting Holmes (1986)). They did however find that the results based on the gender of the audience of the speaker had a significant influence on "their use of epistemic sort of and confident you know." The analysis presented in this short paper focuses on the use of hedging in participatory design, whether and how this varies by gender, and what implications this might have for PD approaches to Design.

What can be defined as 'hedging' is somewhat subjective and retrospective as it is difficult to tell when hedging is used deliberately, for example to seem more approachable, or when it used due to genuine uncertainty. This is supported by Holmes (1986) and Fraser (2010) dissecting how hedging can lead to misinterpretation when used in the incorrect part of a sentence, for example when discussing how intelligent 'John' is, you might say "sort of, John is smart" or by placing the hedge in the wrong part of the sentence, the meaning may change entirely accidentally with "John is sort of smart." The potential for miscommunication is one that could be investigated in significant detail when observing innovation in a group setting to see if this hinders or helps the process. For example, could misinterpretation generate a stronger idea? Or will it simply 
frustrate the participants? It is therefore important to reflect upon literature that focuses on hedging and gender and to carry out research on possible gendered uses of hedging. Is it used as frequently but in different ways? Do we notice it more in one gender? Or is there simply no difference? These research questions are the focus of this short paper.

\section{METHODOLOGY}

PD, has a set structure as a research methodology including; "initial exploration of work", "discovery process" and "prototyping" (Spinuzzi, 2005). In this study, the "initial exploration" took the form of an innovation workshop; a style of focus group, where participants are encouraged to adopt an innovative and creative thinking style. In this instance this included; independent ideation around problem areas, followed by collaborative grouping. The "discovery process" was done through independent ideation of solutions around those problem areas, with the "prototyping" being carried out by the group at large. Ideation, in this instance, refers to the process of noting ideas around a topic on a sticky note. Many innovation workshops are based around this method of ideation; the differences lie in the topics of ideation and how these are derived (Silverstein, Samuel and DeCarlo, 2013).

This research builds on the use of conversation analysis (CA) (Stokoe and Weatheral, 2002), to provide "the tools to explore in fine detail how issues around gender are occasioned in talk" (Stokoe and Smithson, 2001). This study uses a very rudimentary form of CA to uncover any gender differences in the use of hedging within PD. The study involved seven University students (five identified themselves as female, and two identified themselves as male) in an innovation workshop with the aim of designing digital solutions to help with their academic studies. This was run as part of the IT system service's innovation department at the University. Innovation workshops tie strongly into the journey of PD because participants are innovating and carrying out PD as it relates to their own experience as University students who are also the target audience of the product to be designed. In this instance, this is to be a digital solution to support students in their academic studies. The workshop began with ideation around problems with their academic lives, then participants were asked to present their problems to the group. After categorisation and independent ideation of solutions, they were then asked to combine their solutions. It is these transcribed discussions that this paper considers.

From the transcripts, a list of "hedging" terms were listed, categorised and contextualised for analysis. This was done using existing hedging terms such as "I think", "you know" and "sort of" (Murphy, 2010, Holmes, 1986, Holmes, 1990) and considering the importance of context (Gribanova and Gaidukova, 2019). Analysis was then carried out based on the number of occurrences of hedging based on gender, considering the distribution of gender in the group, as well the context. As well as a basic numerical analysis on which terms were more popular with each gender, the context was then analysed in further detail, since the aim of this paper is to uncover exactly how hedging is used differently between genders, not just how frequently.

\section{RESULTS AND ANALYSIS}

The initial research carried out on the transcripts revealed many examples of hedging. Table 1, below, shows the list of terms classified as "hedging" terms (Murphy, 2010, Holmes, 1986, Holmes, 1990) as well as "kind of" and "maybe" which this study choses to define as hedging terms. They were only recorded in the results when clearly used as hedging, not in discussion. The "context" column refers to how they were used, be it to express uncertainty or to persuade the other participants or the facilitator, adapted from Fraser (2010) and Holmes (1986). The average use per gender columns were calculated by dividing the number of uses by that gender by the number of participants of that gender to account for the uneven distribution (two men and five women). 
Table 1. A list of hedging terms and their frequency of use by gender, as well as an average to account for an uneven mix of gender in participants

\begin{tabular}{|l|l|l|l|l|l|}
\hline Term & Context & $\begin{array}{l}\text { Uses by } \\
\text { men }\end{array}$ & $\begin{array}{l}\text { Uses by } \\
\text { women }\end{array}$ & $\begin{array}{l}\text { Average use of } \\
\text { hedge per man }\end{array}$ & $\begin{array}{l}\text { Average user of } \\
\text { hedge per woman }\end{array}$ \\
\hline "I think" & $\begin{array}{l}\text { Expressed } \\
\text { uncertainty }\end{array}$ & 3 & 14 & $\mathbf{1 . 5}$ & $\mathbf{2 . 8}$ \\
\hline "Kind of" or "kinda" & $\begin{array}{l}\text { Expressed } \\
\text { uncertainty }\end{array}$ & 1 & 20 & $\mathbf{0 . 5}$ & $\mathbf{4}$ \\
\hline "Maybe" & Persuasion & 5 & 5 & $\mathbf{2 . 5}$ & $\mathbf{1}$ \\
\hline $\begin{array}{l}\text { "Sort of" } \\
\text { "You know" or }\end{array}$ & $\begin{array}{l}\text { Expressed } \\
\text { uncertainty }\end{array}$ & 1 & 2 & $\mathbf{0 . 5}$ & $\mathbf{0 . 4}$ \\
\hline
\end{tabular}

Uses of "I think" were discounted when opinions were being discussed in categorisation as this was a use of language and not a case of hedging, as can be seen below in Excerpts 1 and 2. An example of "I think" used as hedging can be seen in Excerpt 2. This was also done with the other terms, and they were only noted as a hedging use if the context supported this. Cases of "um" and "er" have also been discounted as, although they were used frequently, they were used more by participants as a means of delay.

Excerpt 1. An example of "I think" being discounted due to context:

M2: So which do you guys think is the biggest problem?

F7: I think the library is probably one of the bigger problems.

M2: $\quad$ Ok

F7: $\quad$ So...

M2: What do you guys think?

Excerpt 2. An example of "I think" being used as hedging:

F1: $\quad$ Um... Some lecturers don't use the interactive screen, so, um, so I think you want more people to use it... So...

As can be seen in the Table 1, hedges such as "kind of" and "I think" were used more frequently by women to express uncertainty. But this difference is not statistically significant as the p value is 0.472 which is more than our stated p value 0.05 , which can be seen in Table 2 .

Table 2. A calculation of the statistical difference between the frequency of hedging between men and women

\begin{tabular}{|l|l|l|}
\hline & Average use of hedging by men & Average use of hedging by women \\
\hline Mean & 1.2 & 1.8 \\
\hline Variance & 0.7 & 2.36 \\
\hline $\mathrm{P}(\mathrm{T}<=\mathrm{t})$ two-tail & $\mathbf{0 . 4 7 2 1 9 2 3 2 5}$ & \\
\hline
\end{tabular}

It could also have been argued that the use, or category, of hedging varied between gender, however the results for this are also not significant, as can be seen in Table 3 for persuasive hedging and Table 4 for expression of uncertainty, because both 0.463 , for persuasive, and 0.299 , for uncertainty, are also both more than 0.05 (our stated p value).

Table 3. A calculation of the statistical difference between the frequency of hedging between men and women for terms categorised as 'persuasion'

\begin{tabular}{|l|l|l|}
\hline & $\begin{array}{l}\text { Average use of persuasive hedging } \\
\text { by men }\end{array}$ & $\begin{array}{l}\text { Average use of persuasive hedging } \\
\text { by women }\end{array}$ \\
\hline Mean & 1.75 & 0.9 \\
\hline Variance & 1.125 & 0.02 \\
\hline $\mathrm{P}(\mathrm{T}<\mathrm{t})$ two-tail & $\mathbf{0 . 4 6 3 0 4 7 1 8 2}$ & \\
\hline
\end{tabular}


Table 4. A calculation of the statistical difference between the frequency of hedging between men and women for terms categorised as 'expressed uncertainty

\begin{tabular}{|l|l|l|}
\hline & $\begin{array}{l}\text { Average use of uncertainty hedging } \\
\text { by men }\end{array}$ & $\begin{array}{l}\text { Average use of uncertainty hedging } \\
\text { by women }\end{array}$ \\
\hline Mean & 0.833333333 & 2.4 \\
\hline Variance & 0.333333333 & 3.36 \\
\hline $\mathrm{P}(\mathrm{T}<=\mathrm{t})$ two-tail & $\mathbf{0 . 2 9 3 4 5 2 7 3 4}$ & \\
\hline
\end{tabular}

All the above results show a similar frequency of hedging used by both male and female participants, and supports the findings by Dixon and Foster (1996), but contradicts the differences found by Holmes (1986). Of course the statistical analysis is impacted by the rather small sample and further workshops might provide further and more conclusive evidence. Clearly too there is a need to research some of the more contextual features of the various 'hedging' utterances through both observation and especially through interviewing - "when you said 'maybe' here, what were you thinking? Why did you use that particular term?"

\section{CONCLUSION}

While Murphy (2010) states "the use of hedges among females before a key word" is used "to avoid the appearance of playing the expert". our analysis found no statistically significant gender differences in how hedging was used. The data is interesting and perhaps suggestive but, unfortunately, not statistically significant. Sample size has an impact on this but perhaps there is a need for more subtle, more contextual, analysis. Perhaps the issue may be that each occurrence of hedging is being treated as equal, and a more subtle analysis of 'hedging' is required to truly determine if there are any gender differences at play in group interaction in PD. The differences in past research (Holmes, 1986, Dixon and Foster, 1997, Stokoe and Smithson, 2001, Stokoe and Weatheral, 2002) show that this lack of statistically significant results may not be all it appears, in fact it could be suggested that it simply shows the need for a more subtle means of analysis. Perhaps using only two hedging categories was not enough, or perhaps as Murphy (2010) and Fraser (2010) suggest, it is important to consider exactly where in an utterance a 'hedging' term is used. Therefore, this paper concludes that further research and contextual analysis and more detailed transcription is required. With past research showing contradictory findings of any relationship between gender and hedging (Holmes, 1986, Dixon and Foster 1996), this paper has shown that the frequency of hedging (from predefined utterances classified as hedging) is used on average no more frequently or infrequently based on the gender of the participant. This is not to say, however, that there are no differences at all. Further research will be carried out to take into account the contextual features of conversation; to find out if where in an utterance, and in what circumstances, hedging varies by gender, or by gender identity. This extended research may also include how this impacts the artefacts created. Overall, this research suggests that the topic requires further research, not least because of its implications for the process and value of PD, the design of PD workshops and consideration of the role of workshop facilitators in considering and regulating the effects of 'hedging' in design discussions. If workshop facilitators learn to recognise the differential use of 'hedging' terms by participants then they can respond in various ways and hopefully improve the value of workshop discussions, through acknowledging the importance of giving voice and parity, ensuring group dynamics and outcomes that properly reflect the views of all participants.

\section{ACKNOWLEDGEMENT}

With thanks to Dr Lynne Blair and Dr Mark Rouncefield for their support and guidance, and to the anonymous reviewers for their advice and feedback. 


\section{REFERENCES}

Bleijenbergh, I. and Van Engen, M. (2015). Participatory modelling to support gender equality. Equality, Diversity and Inclusion: An International Journal.

Brulé, E. and Spiel, K. (2019), June. Negotiating gender and disability identities in participatory design. In Proceedings of the 9th International Conference on Communities \& Technologies-Transforming Communities (pp. 218-227).

Buchmüller, S., Joost, G., Bessing, N. and Stein, S. (2011). Bridging the gender and generation gap by ICT applying a participatory design process. Personal and Ubiquitous Computing, 15(7), p.743.

Crabtree A., Tolmie P., Rouncefield M. (2013). "How Many Bloody Examples Do You Want?" Fieldwork and Generalisation. Proceedings of the 13th European Conference on Computer Supported Cooperative Work, 21-25 September 2013, Paphos, Cyprus. Springer, London

Dixon, J. and Foster, D. (1997). Journal of Psycholinguistic Research, 26(1), pp.89-107.

Fraser, B. (2010). Pragmatic Competence: The Case of Hedging. New Approaches to Hedging, pp.15-34.

Gribanova, T. and Gaidukova, T. (2019). Hedging in different types of discourse. Training Language and Culture, 3(2), pp.85-99.

Hansen, N., Dindler, C., Halskov, K., Iversen, O., Bossen, C., Basballe, D. and Schouten, B. (2019). How Participatory Design Works. Proceedings of the 31st Australian Conference on Human-Computer-Interaction.

Holmes, J. (1986). Functions of You Know in Women's and Men's Speech. Language in Society, 15(1), pp.1-21.

Holmes, J. (1990). Hedges and Boosters in Women's and Men's Speech. Language \& Communication, 10(3), pp.185-205.

Hyland, K. (1996). Writing Without Conviction? Hedging in Science Research Articles. Applied Linguistics, 17(4), pp. 433-454.

Murphy, B. (2010). Corpus and sociolinguistics: investigating age and gender in female talk, Amsterdam; Philadelphia: John Benjamins Pub. Co.

Rommes, E. (2006). Gender sensitive design practices. In Encyclopedia of gender and information technology (pp. 675-681). IGI Global.

Silverstein, D., Samuel, P. and DeCarlo, N. (2013). The Innovator's Toolkit. 2nd ed. Hoboken, N.J.: Wiley.

Spinuzzi, C. (2005). The Methodology of Participatory Design. Applied Theory, 52(2), pp.163-174.

Stokoe, E. and Smithson, J. (2001). Making Gender Relevant: Conversation Analysis and Gender Categories in Interaction. Discourse \& Society, 12(2), pp.217-244.

Stokoe, E. and Weatheral, A. (2002). Gender, language, conversation analysis and feminism. Discourse \& Society, 13(6), pp.707-713. 